\title{
Parental stress in families of 2 year old extremely low birthweight infants
}

\author{
V Tommiska, M Östberg, V Fellman
}

Arch Dis Child Fetal Neonatal Ed 2002;86:F161-F164

See end of article for authors' affiliations

.....................

Correspondence to: Dr Tommiska, National

Research and Development

Center for Welfare and

Health, STAKES/

Syntymärekisteri, PL 220 ,

000531 Helsinki, Finland;

viena.tommiska@pp.fimnet.fi

Accepted

22 November 2001

\begin{abstract}
Objective: To compare the parental stress in the families of 2 year old extremely low birthweight (ELBW) infants with that in control families, and to compare the stress of mothers with that of fathers.

Methods: The study population included all parents of ELBW infants (birth weight $<1000 \mathrm{~g}$ and gestational age at least 22 gestational weeks) born between 1 January 1996 and 31 December 1997 in Helsinki University Hospital and followed at the hospital's neuropaediatric department. The parents of full term, healthy infants born subsequent to each ELBW infant were eligible for the control group. The Swedish Parenthood Stress Questionnaire (SPSQ) translated into Finnish was completed by parents during the neurological assessment visit at 2 years of age.

Results: No significant differences were found in total SPSQ or subscale scores when mothers of ELBW infants were compared with control mothers. Nor did the scores of fathers of ELBW infants differ from the scores of control fathers. However, in the comparison of all mothers with all fathers, several differences were found: mothers indicated significantly more distress than fathers with respect to role restriction, incompetence, and spouse relationship problems, and fathers indicated significantly more distress on the social isolation subscale.

Conclusion: The study shows that, although the birth of an ELBW infant is a stressful event for parents, most parents seem to have recovered well by the time the child has reached the age of 2 . In both control families and those of ELBW infants, the overall stress of mothers seemed to be higher than that of fathers.
\end{abstract}

O wing to advances in perinatal and neonatal care, the survival of prematurely born infants, especially those with extremely low birth weight $(<1000 \mathrm{~g})$, has improved significantly during the last few decades. ${ }^{1-4}$ In spite of the improved survival, the percentage of extremely low birth weight (ELBW) infants with adverse neurological outcome has remained constant, resulting in a growing number of disabled children. ${ }^{56}$ The birth of an ELBW infant is considered a stressful event for the parents. ${ }^{7-9}$ Neonatal intensive care may be frightening, with worries about the infant's survival and disability. ${ }^{9-11}$ Parents may also feel confused because of the changed parenting role during the long hospital stay. ${ }^{10}$ After discharge from hospital, during the first few years, the daily care of an ELBW infant is more time consuming and laborious, with feeding difficulties, special nourishment requirements, and medication. Uncertainties about the future may continue after the neonatal period, as the child grows and confronts new problems: in addition to common sensory-neural disabilities, ELBW infants have a high risk of slight delays in motor and verbal development, behavioural and emotional problems, and minor learning disabilities. ${ }^{12}$

In this study, we aimed to compare parental stress in families of ELBW infants with that in control families, and also to compare the stress experience of mothers with that of fathers when the infants had reached 2 years of corrected age. All infants in the patient group needed prolonged intensive care postnatally and close developmental follow up after the discharge. Our hypothesis was that parents of ELBW infants would still, two years after the initial intensive care period, feel more stress and have more difficulties in relationships with their child, spouse, and friends than parents of full term infants.

\section{SUBJECTS AND METHODS}

Study population and controls

Of the 109 liveborn infants born in Helsinki University Hospital from 1 January 1996 to 31 December 1997, 86 (79\%) were alive at the age corresponding to 40 gestational weeks, and 78 infants from 74 families (four twin pairs) were seen in the same hospital at the corrected age of 24 months. Of the remaining eight infants, two had died and six families lived outside the Helsinki region. Four families were not eligible for the study because of language or recruitment problems. The entire study group consisted of families of 74 ELBW infants. The infants in the study population form a subgroup in a national cohort, which was followed until the corrected age of two years. ${ }^{13} 14$

The control group consisted of 75 families of full term infants born after each ELBW infant in the same hospital (in 1996 the subsequent infant, in 1997 two subsequent children). The inclusion criteria for control infants were: gestational age $\geqslant 37$ weeks, no need for medical care during the first three days, native language of the family Finnish, Swedish, or English.

A national ELBW infant register, established in 1996, included the background information of the ELBW infants and their controls. This information was cross checked with the national birth register ${ }^{15}{ }^{16}$ (table 1 ).

Infants with birth weight below -2 SD according to Finnish intrauterine growth charts were classified as small for gestational age. ${ }^{17}$ Gestational age was estimated on the basis of ultrasound examination before the end of 20 gestational weeks $(96 \%$ of the ELBW infants and $89 \%$ of the control

Abbreviations: ELBW, extremely low birthweight; SPSQ, Swedish Parenthood Stress Questionnaire 
Table 1 Baseline characteristics of the extremely low birthweight (ELBW) infants and their controls

\begin{tabular}{llll}
\hline & ELBW infants $\left(\mathrm{n}=70^{*}\right)$ & Controls $(\mathrm{n}=75)$ & $\mathrm{p}$ Value \\
\hline Mother's mean age (years) & 32.2 & 32.0 & 0.820 \\
Upper social classes 1-2 & $45(64)$ & $62(83)$ & 0.012 \\
Lower social classes 3-4 & $25(36)$ & $13(17)$ & 0.012 \\
Mother's smoking & $12(17)$ & $9(12)$ & 0.379 \\
Primiparity & $41(58)$ & $26(35)$ & 0.004 \\
Average number of children in family & 0.67 & 0.88 & 0.164 \\
Response rate of mothers & $56(80)$ & $66(88)$ & 0.137 \\
Response rate of fathers & $23(33)$ & $38(51)$ & 0.039 \\
Birth weight (g) & $780(447-995)$ & $3671(2530-5250)$ & $<0.001$ \\
Gestational age (weeks) & $27.1(23.7-32.6)$ & $39.9(37.3-42.1)$ & $<0.001$ \\
Assessment age (years) & $2.24(2.12-2.56)$ & $2.22(1.91-2.73)$ & 0.524 \\
Male & $37(50)$ & $39(52)$ & 0.807 \\
SGA & $35(47)$ & $1(1)$ & $<0.001$ \\
Multiple pregnancy infants & $16(22)$ & $2(3)$ & $<0.001$ \\
Bayley scores <70 & $1(1)$ & 0 & 0.497 \\
Blindness at the age of 2 years & 0 & 0 & 0.245 \\
Cerebral palsy at the age of 2 years & $3(4)$ & 0 & \\
\hline Values are either number (\%) or mean (range). & & \\
*n=74 for infant parameters (birth weight, etc). & & \\
SGA, Small for gestational age. & & & \\
&
\end{tabular}

infants) or on the last menstrual period. Standard diagnostic criteria were used for blindness. ${ }^{18}$ Cerebral palsy was defined at the age of 18 months as a non-progressive motor impairment with brisk tendon reflexes, positive Babinski's sign, and persistent primitive reflexes. Allocation of social class was based on mother's education or occupation, and four classes were used. ${ }^{19}$ In the analysis, the upper two and lower two classes were combined.

\section{Methods}

At the age of 24 months corrected for gestational age, a neurological examination and developmental age assessment with Bayley Infant Scale 2nd edition ${ }^{20}$ were performed on ELBW infants at the neuropaediatric department of Helsinki University Hospital. During the visit the parents of ELBW infants were invited to join the study and to fill in the Swedish Parenthood Stress Questionnaire (SPSQ) ${ }^{21} 22$ translated into Finnish. The SPSQ is based on parts of the Parent Domain of the American Parenting Stress Index. ${ }^{23}$

Control families were invited to join the study by letter and, after parental consent, the child was assessed at the age of 2 years with the same developmental methods as the ELBW children. A total of 75 families (60\%) out of 126 invited were studied, and all accompanying parents completed the questionnaire during the visit. The control families who agreed to participate did not differ from those who did not with regard to mother's age, social class, mother's smoking habits, mean number of previously born children in the family, children's sex, mean birth weight, and gestational age, and number of multiple pregnancy infants.

The SPSQ contains 34 items divided into five subscales designated incompetence, role restriction, social isolation, spouse relationship problems, and health problems. Each item is scored on a Leikert scale from 1 to 5, the highest score indicating problems or difficulties in a particular area of the parentchild relationship. ${ }^{22}$ Mean scores were calculated for each subscale and for the whole SPSQ. The test method was standardised and validated in Sweden, ${ }^{21} 22$ where the culture and social structure closely resemble those in Finland. The internal consistency of the translated inquiry form was tested by calculating Cronbach's $\alpha$ coefficients for all subscales and the total SPSQ score (table 2). All coefficients except one were above 0.65 , showing that satisfactory internal consistency in most subscales had been achieved.

All statistical analysis was performed using the SPSS program. Pearson's $\chi^{2}$ test, Fisher's exact test, and Student's $t$
Table 2 Reliability coefficients (Cronbach's $\alpha$ based on average interitem correlation) for the total SPSQ and the subscale scores in parents of premature infants (ELBWI group) and parents of control infants (control group)

\begin{tabular}{lll}
\hline & \multicolumn{2}{l}{$\alpha$ coefficients } \\
\cline { 2 - 3 } & $\begin{array}{l}\text { ELBWI group } \\
(\mathrm{n}=79)\end{array}$ & $\begin{array}{l}\text { Control group } \\
(\mathrm{n}=104)\end{array}$ \\
\hline Total SPSQ score & 0.89 & 0.86 \\
Incompetence & 0.86 & 0.80 \\
Role restriction & 0.78 & 0.77 \\
Social isolation & 0.70 & 0.67 \\
Spouse relationship problems & 0.81 & 0.75 \\
Health problems & 0.55 & 0.69 \\
\hline
\end{tabular}

SPSQ, Swedish Parenthood Stress Questionnaire.

test were used as appropriate to distinguish differences between the groups. $\mathrm{p}<0.05$ was considered significant.

\section{RESULTS}

The response rate for mothers was acceptable and that for fathers was low in both groups. No differences were found in any of the stress subscales between the mothers of ELBW infants and the control mothers, nor did the subscale or total SPSQ scores differ between the fathers of ELBW infants and the control fathers (table 3 ).

In the families of ELBW infants, the scores of the mothers did not differ significantly from those of the fathers, whereas the control mothers had higher scores than the control fathers on the role restriction subscale $(p=0.021)$ (table 4$)$. The control mothers seemed also to experience more distress on the incompetence subscale, and the control fathers on the social isolation subscale, but neither of the differences reached full significance $(p=0.059$ and $p=0.052$ respectively; table 4$)$. As the mothers and fathers in the two groups did not seem to differ from each other, the comparisons were made between all mothers and all fathers; several significant differences were found. In the subscales of incompetence $(2.20 \quad v \quad 1.95$; $\mathrm{p}=0.011)$, role restriction $(3.37 \vee 3.04 ; \mathrm{p}=0.008)$, and spouse relationship $(2.39 \vee 2.10 ; \mathrm{p}=0.018)$, mothers had higher scores than fathers, and fathers scored higher than 
Table 3 Comparison of SPSQ total and subscale scores between parents of extremely low birthweight infants (ELBWI) and controls

\begin{tabular}{llllllll}
\hline & \multicolumn{7}{l}{ Subscales } \\
\cline { 5 - 8 } & $N$ & Total SPSQ scores & Incompetence & Role restriction & Social isolation & Spouse relationship & Health problems \\
\hline ELBWI mothers & 56 & $2.41(0.57)$ & $2.19(0.70)$ & $3.32(0.76)$ & $1.97(0.62)$ & $2.46(1.00)$ & $2.10(0.77)$ \\
$\begin{array}{l}\text { Control mothers } \\
\text { p Value }\end{array}$ & 66 & $2.43(0.48)$ & $2.20(0.64)$ & $3.41(0.73)$ & $1.91(0.62)$ & $2.32(0.93)$ & $2.34(0.88)$ \\
& & 0.852 & 0.933 & 0.473 & 0.591 & 0.446 & 0.120 \\
ELBWI fathers & 23 & $2.25(0.51)$ & $1.90(0.62)$ & $3.03(0.84)$ & $2.12(0.66)$ & $2.10(0.67)$ & $2.29(0.67)$ \\
Control fathers & 38 & $2.27(0.40)$ & $1.98(0.44)$ & $3.05(0.79)$ & $2.15(0.54)$ & $2.10(0.60)$ & $2.20(0.72)$ \\
p Value & & 0.866 & 0.582 & 0.920 & 0.836 & 0.979 & 0.606 \\
\hline
\end{tabular}

Values are mean (SD).

SPSQ, Swedish Parenthood Stress Questionnaire.

Table 4 Comparison of SPSQ total and subscale scores between mothers and fathers

\begin{tabular}{|c|c|c|c|c|c|c|c|}
\hline & \multirow[b]{2}{*}{$\mathrm{N}$} & \multirow[b]{2}{*}{ Total SPSQ scores } & \multicolumn{5}{|l|}{ Subscales } \\
\hline & & & Incompetence & Role restriction & Social isolation & Spouse relationship & Health problems \\
\hline ELBWI mothers & 56 & $2.41(0.57)$ & $2.19(0.70)$ & $3.32(0.76)$ & $1.97(0.62)$ & $2.46(1.00)$ & $2.10(0.77)$ \\
\hline ELBWI fathers & 23 & $2.25(0.51)$ & $1.90(0.62)$ & $3.03(0.84)$ & $2.12(0.66)$ & $2.10(0.67)$ & $2.29(0.67)$ \\
\hline $\mathrm{p}$ Value & & 0.259 & 0.081 & 0.146 & 0.361 & 0.074 & 0.307 \\
\hline Control mothers & 66 & $2.43(0.48)$ & $2.20(0.64)$ & $3.41(0.73)$ & $1.91(0.62)$ & $2.32(0.93)$ & $2.34(0.88)$ \\
\hline Control fathers & 38 & $2.27(0.40)$ & $1.98(0.44)$ & $3.05(0.79)$ & $2.15(0.54)$ & $2.10(0.60)$ & $2.20(0.72)$ \\
\hline $\mathrm{p}$ Value & & 0.099 & 0.059 & 0.021 & 0.052 & 0.142 & 0.395 \\
\hline
\end{tabular}

Values are mean (SD).

SPSQ, Swedish Parenthood Stress Questionnaire; ELBWI, extremely low birthweight infants.

mothers on the social isolation subscale (2.14 $v$ 1.94; $\mathrm{p}=0.040)$. The health problem scores did not differ between the groups $(2.23 \times 2.23 ; \mathrm{p}=0.991)$.

\section{DISCUSSION}

Only a few validated methods have been used to measure the stress of parenting. The Parenting Stress Index (PSI) designed by Abidin $^{23}$ has been used in different study populations ${ }^{25-27}$ and has been considered a reliable method for measuring parental stress. The Swedish instrument, SPSQ, influenced by the PSI, has been validated and standardised, ${ }^{21}{ }^{22}$ and proved sensitive and stable in finding differences in parenting problems in certain risk populations. ${ }^{24}$ In our study population, the internal consistency of the full scale and five subscales was acceptable and comparable to the Swedish validation samples. ${ }^{22}$

In our ELBW infants and control group, the mothers differed significantly from each other in several background characteristics. The average social class of control mothers was higher than that of mothers of the ELBW infants. The social class distribution was based on the mother's education or occupation, factors that may have an effect on stress experienced according to previous studies, in which higher maternal education has been associated with lower parental distress. ${ }^{82}$ If social class had any influence on our study results, it would have caused more pronounced differences between SPSQ scores, but no difference was found. The primiparity rate was higher in families of ELBW infants, but no significant difference was found between the average number of children in families

Lower mean birth weight, gestational age, higher incidence of multiple birth infants, and also higher incidence of various disabilities were closely related to reasons for and consequences of extreme prematurity and assumed to be different in the groups. The children's average age at the time of assessment did not differ between the groups.
Stjernqvist, in her study from Sweden, found no relation between permanent neurological injury and strong reactions in family members during the first year of life. ${ }^{7}$ Parallel results have been reported by Lee et $a l_{,}{ }^{28}$ but the opposite was found by Singer et al $^{29}$ and Cronin et al. ${ }^{8}$ Recent studies have also shown that parents of ELBW infants usually graded the harm caused by the functional disability of their child less than did health care professionals, ${ }^{30}{ }^{31}$ and most parents supported life saving interventions in all infants at the limit of viability regardless of the outcome. ${ }^{28}{ }^{31}$ In the present study population, apparent impairments were rare $(n=5)$ : no infant was blind, only one infant had mental Bayley scores below 70, three had diagnosed cerebral palsy, and two an obvious delay in speech development requiring speech therapy.$^{14}$ However, with so few severely disabled infants, we could not investigate the effect of apparent handicaps on parental distress.

Many studies confirm that mothers experience more distress than fathers about their premature infant during the initial period and the prolonged hospital stay and also later after discharge. ${ }^{8-11}$ In the Swedish study, in which parenting stress was measured in parents seeking specialised medical assistance for their young child, fathers had lower total and four subscale scores in SPSQ than mothers. ${ }^{24}$ Only on the social isolation scale were the scores similar in mothers and fathers. In our study, the total stress of mothers was higher, although not significantly so. They also showed greater distress on the subscales of incompetence, role restriction, and spouse relationship problems, and fathers on the social isolation subscale, whereas the health problem scores did not differ between the groups. When parents were divided into groups depending on whether their baby was premature or a control, the patterns were similar, but, because the groups were smaller, some of the differences were no longer significant. Perhaps fathers who accompanied their child to hospital and participated in the study felt a greater responsibility for their child than average fathers and thus may have had reduced opportunities for social activities. The results may 
also refer to traditional role differentiation in which fathers seem to fulfil their main duties outside the home.

Postnatal depression is shown to be greater in mothers of preterm infants. ${ }^{29}{ }^{32}$ In this study, the exact number of mothers with a diagnosis of postnatal depression in not known in either of the groups, but according to previous studies the birth of an ELBW infant is considered to be a crisis for both parents. ${ }^{7}$ However, our results show that after 2 years, most parents, at least, had coped well with the situation and recovered, appearing not to have any greater stress than parents of full term infants of the same age. Although this finding contradicts the results of some previous investigations, ${ }^{78}$ similar findings have also been reported..$^{283}$

The importance of parenting stress has been realised over the last few decades. In several studies, parental distress was found to be related to the delay in the infant's cognitive and neurological development. ${ }^{29}{ }^{34} 35$ Parental support and intervention programmes have been shown to reduce maternal distress and probably promote the infant's development. ${ }^{36}{ }^{37}$ In our study population, the parents of an ELBW infant seemed to have recovered well from the initial shock, but the group of severe handicapped infants in our study population was too small to allow detection of possible problems in that special group. As psychosocial factors seem to play an important role in the neurological development of ELBW infants, reducing or increasing the effects of the perinatal and neonatal medical risk factors, the well being of the parents must be considered an important challenge to modern neonatal and paediatric care.

\section{ACKNOWLEDGEMENTS}

This study was supported by grants from the Finnish Pediatric Foundation and Signe and Ane Gyllenberg Foundation.

\section{Authors' affiliations}

V Tommiska, V Fellman, Hospital for Children and Adolescents, University of Helsinki, Finland

M Östberg, Department of Psychology, University of Uppsala, Sweden

\section{REFERENCES}

1 Svenningsen NW, Bjorklund L, Lindroth $M$. Changing trend in perinatal management and outcome of extremely low birthweight (ELBW) infants. Acta Paediatr Suppl 1997;422:89-91.

2 The Victorian Infant Collaborative Study Group. Improved outcome into the 1990s for infants weighing 500-999 g at birth. Arch Dis Child Fetal Neonatal Ed 1997;77:F91-4.

3 Grögaard JB, Lindstrom DP, Parker RA, et al. Increased survival rate in very low birth weight infants (1500 grams or less): no association with increased incidence of handicaps. J Pediatr 1990;1 17:139-46.

4 Hack M, Friedman H, Fanaroff AA. Outcomes of extremely low birth weight infants. Pediatrics 1996:98:931-7.

5 O'Shea TM, Klinepeter KL, Goldstein DJ, et al. Survival and developmental disability in infants with birth weights of 501 to 800 grams, born between 1979 and 1994. Pediatrics 1997;100:982-6.

6 Emsley HC, Wardle SP, Sims DG, et al. Increased survival and deteriorating developmental outcome in 23 to 25 week old gestation infants, 1990-4 compared with 1984-9. Arch Dis Child Fetal Neonatal Ed 1998;78:F99-104.

7 Stjernqvist KM. Extremely low birth weight infants less than $901 \mathrm{~g}$ Impact on the family during the first year. Scand J Soc Med 1992;20:226-33.

8 Cronin CM, Shapiro CR, Casiro OG, et al. The impact of very low birth weight infants on the family is long lasting. A matched control study. Arch Pediatr Adolesc Med 1995;149:151-8.

9 Trause MA, Kramer LI. The effects of premature birth on parents and their relationship. Dev Med Child Neurol 1983,25:459-65.
10 Miles MS, Funk SG, Kasper MA. The stress response of mothers and fathers of preterm infants. Res Nurs Health 1992;15:261-9.

11 Benfield DG, Lieb SA, Reuter J. Grief response of parents after referral of the critically ill newborn to a regional center. N Engl J Med 1996;294:975-8.

12 Halsey CL, Collin MF, Andeson CL. Extremely low birth weight children and their peers: a comparison of preschool performance. Pediatrics 1993:91:807-11.

13 Tommiska V, Heinonen K, Ikonen S, et al. A national short-term study of extremely low birth weight infants born in Finland in 1996-1997. Pediatrics 2001;107:e2

14 Tommiska V, Heinonen K, Kero P, et al. A national 2-year follow-up study of extremely low birth weight infants born in 1996-1997. Arch Dis Child Fetal Neonatal Ed (in press).

15 Koskinen R, Meriläinen J, Gissler M, et al. Finnish Perinatal Statistics 1996. Statistical report $31 / 1998$. Helsinki: National Research and Development Center for Welfare and Health, 1998.

16 Koskinen R, Meriläinen J, Gissler M, et al. Finnish Perinatal Statistics 1997-1998. Statistical report 41/1999. Helsinki: National Research and Development Center for Welfare and Health, 1999.

17 Pihkala J, Hakala T, Voutilainen $\mathrm{P}$, et al. [Characteristic of recent fetal growth curves in Finland.] Duodecim 1989;105:1540-6.

18 Steinkuller PG, Du L, Gilbert A, et al. Childhood blindness. J AAPOS 1999;3:26-32.

19 Gissler M, Rahkonen O, Jarvelin MR, et al. Social class differences in health until the age of seven years among the Finnish 1987 birth cohort. Soc Sci Med. 1998;46: 1543-52.

20 Bayley N. Bayley scales of infant development. 2nd ed. San Antonio, TX: Psychological Corporation, 1993.

21 Östberg M, Hagekull B. A structural modeling approach to the understanding of parenting stress. J Clin Child Psychol 2000;29:615-25

22 Östberg $M$, Hagekull B, Wettergren S. A measure of parental stress in mothers with small children. Dimensionality, stability and validity. Scand J Psychol 1997;38:199-208.

23 Abidin RR. Parenting Stress Index. PSI manual. Odessa, FL:Psychological Assessment Resources Inc, 1990

24 Östberg M. Parental stress, psychosocial problems and responsiveness in help-seeking parents with small (2-45 months old) children. Acta Pediatr 1998;87:69-76.

25 Hauenstein EJ, Marvin RS, Snyder AL, et al. Stress in parents of children with diabetes mellitus. Diabetes Care 1989;12:18-23.

26 Mattie-Luksic M, Javornisky G, DiMario FJ. Assessment of stress in mothers of children with severe breath-holding spells. Pediatrics 2000, 106: 1-5

27 Freeman NL, Perry A, Factor DC. Child behaviours as stressors: replicating and extending the use of the CARS as a measure of stress: a research note. J Child Psychol Psychiatry 1991;32:1025-30.

28 Lee SK, Penner PL, Cox M. Impact of very low birth weight infants on the family and its relationship to parental attitudes. Pediatrics 1991;88:105-9.

29 Singer LT, Salvator A, Guo S, et al. Maternal psychological distress and parenting stress after the birth of a very low-birth-weight infant. JAMA 1999;281:799-805.

30 Saigal S, Burrows E, Stoskopf BL, et al. Impact of extreme prematurity on families of adolescent children. J Pediatr 2000;137:701-6.

31 Saigal S, Rosenbaum PL, Freeny D, et al. Parental perspectives of the health-related quality of life of teen-aged children who were extremely low birth weight and term controls. Pediatrics 2000;105:569-74.

32 Meyer EC Garcia Coll CT, Seifer R et al. Psychological distress in mothers of preterm infants. J Dev Behav Pediatr 1995;16:412-17.

33 Saigal S, Stoskopf BL, Freeny D, et al. Differences in preferences for neonatal outcomes among health care professionals, parents, and adolescents. JAMA 1999:28:1991-7.

34 Miceli PJ, Goeke-Morey MC, Whitman TL, et al. Brief report: birth status, medical complications, and social environment: individual differences in development of preterm, very low birth weight infants. J Pediatr Psychol 2000;25:353-8.

35 Thompson RJ, Goldstein RF, Oehler JM, et al. Developmental outcome of very low birth weight infants as a function of biological risk and psychosocial risk. J Dev Behav Pediatr 1994;15:232-8.

36 Meyer EC, Coll CT, Lester BM, et al. Family-based intervention improves well-being and feeding interaction of preterm infants. Pediatrics 1994;93:241-6.

37 Avon Premature Infant Project. Randomised trial of parental support for families with very preterm children. Arch Dis Child Fetal Neonatal Ed 1998;79:F4-11. 